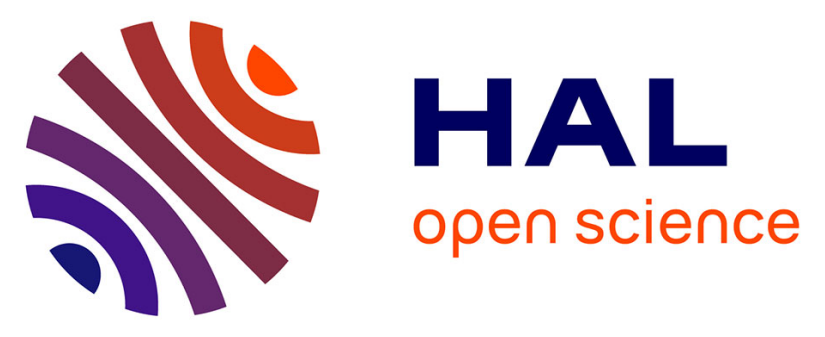

\title{
Evaluation of commonly used tests to measure the effect of single-dose aspirin on mouse hemostasis
}

\author{
Benoit Decouture, Alexandre Leuci, Blandine Dizier, Tiphaine \\ Belleville-Rolland, Alexandre Mansour, Fanny Martin, Dominique Pidard, \\ Pascale Gaussem, Christilla Bachelot-Loza
}

\section{To cite this version:}

Benoit Decouture, Alexandre Leuci, Blandine Dizier, Tiphaine Belleville-Rolland, Alexandre Mansour, et al.. Evaluation of commonly used tests to measure the effect of single-dose aspirin on mouse hemostasis. Prostaglandins, Leukotrienes and Essential Fatty Acids, 2019, 149, pp.46-51. 10.1016/j.plefa.2019.08.002 . inserm-02355824

\section{HAL Id: inserm-02355824 https://www.hal.inserm.fr/inserm-02355824}

Submitted on 8 Nov 2019

HAL is a multi-disciplinary open access archive for the deposit and dissemination of scientific research documents, whether they are published or not. The documents may come from teaching and research institutions in France or abroad, or from public or private research centers.
L'archive ouverte pluridisciplinaire HAL, est destinée au dépôt et à la diffusion de documents scientifiques de niveau recherche, publiés ou non, émanant des établissements d'enseignement et de recherche français ou étrangers, des laboratoires publics ou privés. 
Evaluation of commonly used tests to measure the effect of single-dose aspirin on mouse hemostasis

Benoit DECOUTURE ${ }^{1 \#}$, Alexandre LEUCl ${ }^{1 \#}$, Blandine DIZIER $^{1}$, Tiphaine BELLEVILLE-ROLLAND ${ }^{1,2}$, Alexandre MANSOUR ${ }^{1}$, Fanny MARTIN ${ }^{1}$, Dominique PIDARD ${ }^{1}$, Pascale GAUSSEM $^{1,2^{*}}$ and Christilla BACHELOT-LOZA ${ }^{1 *}$

\# These authors equally contributed to the work.

* PG and CBL share equal senior authorship

${ }^{1}$ Université de Paris, Innovative Therapies in Haemostasis, INSERM, F-75006 Paris, France,

${ }^{2}$ Université de Paris, Innovative Therapies in Haemostasis, INSERM, F-75006 Paris, France, Service d'Hématologie Biologique, AH-HP, Georges Pompidou European Hospital, F-75015 Paris, France

Corresponding author:

Prof Pascale Gaussem

Inserm UMR_S1140, Faculté de Pharmacie, 4 av de l'Observatoire, F-75006 Paris, France

e-mail : pascale.gaussem@aphp.fr

phone: +33156093936 


\section{Abstract}

Discrepancies in preclinical studies of aspirin (ASA) antiplatelet activity in mouse models of bleeding and arterial thrombosis led us to evaluate commonly reported methods in order to propose a procedure for reliably measuring the effects of single dose ASA on mouse hemostasis. FVB and C57Bl6 mice received $100 \mathrm{mg} / \mathrm{kg}$ of ASA or vehicle orally $30 \mathrm{~min}$ or $3 \mathrm{~h}$ prior to investigate either hemostasis using the tail bleeding assay or carotid thrombosis induced by $\mathrm{FeCl}_{3}$, or to blood sampling for isolated platelet aggregation and $\mathrm{TXB}_{2}$ generation.

Expected inhibition of COX1 by ASA was ascertained by a strong decrease in TXB 2 production, and its effect on platelet function and hemostasis, by decreased collagen-induced aggregation and increased bleeding time, respectively. Strikingly, we determined that anti-hemostatic effects of ASA were more predictable $30 \mathrm{~min}$ after administration than $3 \mathrm{~h}$ later. Conversely, ASA did not alter time to arterial occlusion of the carotid upon $\mathrm{FeCl}_{3}$-induced thrombosis, suggesting ASA not to be used as reference inhibitor drug in this model of arterial thrombosis.

Key-words: aspirin, hemostasis, platelets, preclinical study, thrombosis 


\section{Background}

Acetyl salicylic acid (ASA or aspirin) at low dose is broadly used for its antiplatelet effect in primary and secondary prevention of cardiovascular diseases [1]. ASA irreversibly acetylates the Ser529 residue of COX1, thereby leading to a steric hindrance of the COX channel that prevents access of the substrate to the catalytic site of the enzyme [2]. COX1 is responsible for the conversion of arachidonic acid into prostaglandins, that are precursors of thromboxane $A_{2}$ $\left(\mathrm{TXA}_{2}\right)$ in platelets [3]. By binding the thromboxane and prostanoid receptor (TP receptor), platelet-secreted $\mathrm{TXA}_{2}$ enhances platelet activation initially triggered by agonists such as collagen. By limiting one major amplification pathway of platelet activation [4], ASA is therefore a relevant comparator for preclinical studies of antiplatelet agents under development.

Interestingly, whereas ASA pharmacology is well known in humans, its antiplatelet activity is inconsistently described in mouse models. The discrepancies between studies, such as inconsistent effects on mouse arterial thrombosis or bleeding time, could be the consequence of differences regarding the animal strain, the route of administration and ASA doses, as well as the hemostatic parameters evaluated in vivo and ex vivo. Doses most frequently found in the literature may vary from 1 to $100 \mathrm{mg} / \mathrm{kg}$, given as single or repeated doses [5]-[10]. Various routes are also reported: intravenous, oral, intraperitoneal or subcutaneous. Whereas the most used bleeding model is the tail-tip transection, arterial thrombosis models in use are more diverse. Indeed, arterial thrombosis of carotid, cremaster or mesenteric artery may be induced by $\mathrm{FeCl}_{3}$, laser or mechanical injury [11]. Finally, the delay of testing the effect of ASA after administration may vary from 10 min to $24 \mathrm{~h}$ after administration [7], [9], [12]. 


\section{Objectives}

Starting from commonly used experimental conditions concerning delivery of ASA and testing its antiplatelet effects in mice, our aim was to determine a procedure for reliably measuring the effects of single dose ASA on mouse hemostasis.

\section{Methods}

\section{Animals}

FVB and C57BI6 (C57BL/6NRj) mice (males, 8-12 weeks old; weight 27.6 gr \pm 2.3 , mean \pm SD) were from Janvier Labs (Le Genest-Saint-Isle, France). Anesthesia was induced by intraperitoneal injection of $80 \mathrm{mg} / \mathrm{kg}$ ketamine (Clorketam ${ }^{\circledR}$ 1000, Vetoquinol, Lure, France) and $10 \mathrm{mg} / \mathrm{kg}$ xylasine (Rompun ${ }^{\circledR} 2 \%$, Bayer, La Garenne-Colombe, France), or with 2.5\% inhaled isofluorane (Vetflurane ${ }^{\circledR}$, Virbac, Carros, France) when performing tail bleeding time experiments. ASA (DL-lysine acetylsalicytate, Aspegic ${ }^{\circledR}$, Sanofi-Aventis, Gentilly, France) dissolved in distilled water was administered orally by force-feeding or by intraperitoneal (i.p.) injection (100 mg/kg, $10 \mu \mathrm{l} / \mathrm{gr}$ ). In vivo experiments were done by an observer blinded to the treatment group. All animal studies were approved by the Ethics Committee on Animal Resources of Paris Descartes University (registration number: CEEA34.CBL.131.12).

\section{Platelet preparation}

Blood was collected by cardiac puncture into ACD-C solution (13 mM citric acid, $12.6 \mathrm{mM}$ sodium citrate, $11 \mathrm{mM}$ D-glucose) and diluted with wash buffer (36 mM citric acid, $5 \mathrm{mM}$ Dglucose, $5 \mathrm{mM}$ potassium chloride, $2 \mathrm{mM}$ calcium chloride, $1 \mathrm{mM}$ magnesium chloride, $103 \mathrm{mM}$ 
sodium chloride, $\mathrm{pH}$ 6.5) containing apyrase (0.1 U/ml; Sigma-Aldrich, St. Louis, MO, USA) and prostaglandin $\mathrm{E}_{1}\left(\mathrm{PGE}_{1}, 1 \mu \mathrm{M}\right.$; Sigma-Aldrich). Diluted platelet-rich plasma (PRP) was obtained by 7 min centrifugation at $170 \mathrm{~g}$. Platelets were washed twice with wash buffer containing apyrase and $\mathrm{PGE}_{1}$, and then centrifuged for $10 \mathrm{~min}$ at $750 \mathrm{~g}$. The pelleted platelets were resuspended in assay buffer (10 mM HEPES, $140 \mathrm{mM}$ sodium chloride, $3 \mathrm{mM}$ potassium chloride, $5 \mathrm{mM}$ sodium bicarbonate, $0.5 \mathrm{mM}$ magnesium chloride, $10 \mathrm{mM}$ D-glucose, $\mathrm{pH}$ 7.35) to a concentration of $3.5 \times 10^{8} / \mathrm{ml}$. Calcium chloride $2 \mathrm{mM}$ was then added.

\section{Platelet aggregation studies}

Platelet aggregation was measured on a Discovery HT-R microplate reader (MWG Biotech AG, Ebersberg, Germany) coupled to the KC4 software for analysis of the data. FVB mouse washed platelets $\left(3.5 \times 10^{8} / \mathrm{ml}\right)$ were incubated for $2 \mathrm{~min}$ at $37^{\circ} \mathrm{C}$ under stirring in wells of a 96 -well microplate (Greiner Bio-one, Frickenhausen, Germany) in a volume of $90 \mu \mathrm{l}$, then aggregation was induced by adding $5 \mu \mathrm{g} / \mathrm{ml}$ fibrillar type-I collagen from equine Achilles tendon (Horm, Nycomed, Linz, Austria) or 1 MM U46619, a TP synthetic agonist (Calbiochem, Merck, Darmstadt, Germany). Aggregation was monitored for $5 \mathrm{~min}$ and expressed as the percentage change in absorbance at $405 \mathrm{~nm}$ as previously described [13].

\section{Bleeding assay}

Tails of anaesthetized mice were pre-incubated in a $37^{\circ} \mathrm{C}$ saline solution during 5 min to homogenize vessel dilatation between animals. Then, bleeding time was measured following a 3-mm tail-tip transection, and immediate immersion of the tail in $10 \mathrm{ml}$ of isotonic saline at 
$37^{\circ} \mathrm{C}$. Bleeding time was set at cessation of blood leakage for at least $1 \mathrm{~min}$. Blood loss was estimated by measuring the hemoglobin concentration in the saline, using the Drabkin method.

\section{Thrombosis assay}

Mice were anaesthetized and maintained at $37^{\circ} \mathrm{C}$ on a heating plate. The left carotid artery was exposed and dissected away from the vagus nerve and surrounding tissues. Carotid artery blood flow was monitored with a Doppler flow meter equipped with a Transonic flow probe (Model MA0.5PSB, Transonic System Inc, Ithaca, NY). Arterial thrombosis was induced by placing a $15 \%$ $\mathrm{FeCl}_{3}$-saturated filter paper on the artery, $5 \mathrm{~mm}$ upstream the flow probe, for 2 or $4 \mathrm{~min}$. Monitoring of blood flow was maintained for 5 min after the cessation of flow, and the time required for occlusion was recorded.

\section{Thromboxane assay}

Thromboxane $B_{2}\left(T X B_{2}\right)$ level was measured with the thromboxane assay kit from R\&D system (Abingdon, UK). Assays were performed on washed platelet supernatant obtained after collagen-induced platelet aggregation. Ten min after the addition of collagen, 20 mM EDTA was added and the sample were centrifuged $2 \mathrm{~min}$ at $12000 \mathrm{~g}$. The supernatant was kept frozen at $20^{\circ} \mathrm{C}$ until tested.

\section{Data analysis}

Data were expressed as medians [95\% confidence interval $(\mathrm{Cl})$ ] for non-normally distributed variables. Statistical analysis was performed with the Prism software package (GraphPad 
Software, Inc., San Diego, CA, USA). The Mann-Whitney test was used to compare each parameter. Differences were considered significant when $P<0.05$.

\section{Results}

The impact of ASA administration on mouse hemostasis was assessed by varying the time elapsed between ASA administration and testing (30 min versus $3 \mathrm{~h}$ ), as well as the mouse strain (FVB versus C57BI6).

\section{Bleeding experiments}

FVB mice. The impact of the period of time between oral ASA administration and bleeding time measurement was first tested in FVB mice. When ASA was given 30 min before measuring bleeding time, this hemostatic parameter was strongly increased compared to vehicle (88 sec [95\% Cl, 44-95] vs $343 \mathrm{sec}$ [95\% Cl, 250-600] for vehicle and ASA respectively; $P<.0001$; Fig $1 \mathrm{~A}$ ). Conversely, when administered 3 hours before the bleeding assay, ASA inconsistently modified the bleeding time compared to vehicle (161 sec [95\% Cl, 45-600] vs $213 \sec$ [95\% Cl, 99-600] for vehicle and ASA respectively; $P>.05$; Fig $1 \mathrm{~A}$ ), mostly because a high variability in values. However, no significant difference in bleeding time between the ASA groups was observed (30 $\min$ vs $3 h, p=0.16)$.

Compared to bleeding time, measuring blood loss to evaluate the anti-hemostatic effect of ASA was not informative since it did not significantly differ from controls neither $30 \mathrm{~min}$ (14 $\mu$ [ $[95 \%$ $\mathrm{Cl}, 6-29]$ vs $21 \mu \mathrm{l}$ [95\% Cl, 11-97] for control and ASA respectively; $P$ > .05; Fig 1B) nor $3 \mathrm{~h}$ after 
ASA administration $(15 \mu \mathrm{l}[95 \% \mathrm{Cl}, 6-23]$ vs $36 \mu \mathrm{l}[95 \% \mathrm{Cl}, 10-73]$ for control and ASA respectively; $P>.05 ;$ Fig $1 \mathrm{~B})$.

C57B/6 mice. To evaluate the potential relevance of the animal genetic background on responsiveness to ASA, we tested whether the widely used C57BI6 (C57BL/6NRj) strain could give comparable results than the FVB strain. When ASA was given to C57BI6 mice 30 min before the assay, the bleeding time was also found strongly increased (44 sec [95\% Cl, 5-83] vs $320 \mathrm{sec}$ [95\% Cl, 205-600] for control and ASA respectively; $P<.01 ;$ Fig $1 C)$. On another hand, blood loss was significantly, although slightly, increased by ASA $(7.5 \mu \mathrm{l}[95 \% \mathrm{Cl}, 5.8-9.7]$ vs $10.5 \mu \mathrm{l}[95 \% \mathrm{Cl}$, 9-18] for control and ASA respectively; $P<.05$; Fig 1D). However, such as for FVB mice, ASA administered $3 \mathrm{~h}$ before the tail cutting did not modify the bleeding time (53 sec [95\% Cl, 44-64] vs $128 \mathrm{sec}$ [95\% Cl, 5-600] for control and ASA respectively; $P>.05 ;$ Fig $1 \mathrm{C}$ ) nor blood loss values (5.5 $\mu \mathrm{l}[95 \% \mathrm{Cl}, 3.6-13.3]$ vs $10.4 \mu \mathrm{l}[95 \% \mathrm{Cl}, 5.5-83.2]$ for control and ASA respectively; $P>.05$; Fig 1D). No significant difference in bleeding time between the ASA groups was observed (30 $\min$ vs $3 h, p=0.18$, Fig $1 C)$.

\section{Carotid artery thrombosis}

We next tested the impact of ASA on the most commonly used in vivo artery thrombosis model: the $\mathrm{FeCl}_{3}$-induced injury of the carotid artery [11]. Surprisingly, ASA administered by oral route $30 \mathrm{~min}$ or $3 \mathrm{~h}$ before the experiment did not modify the time to the total occlusion whatever the mouse strain, FVB or C57BI6 (Table 1). 
Then, we tested a repeated administration of ASA for 4 days in C57BI6 mice. In order to check if the absence of effect of aspirin on the thrombosis model was not due to a lack of sensitivity of

our method, the $\mathrm{FeCl} 3$ patch was left during only $2 \mathrm{~min}$. Again, no difference in the time to occlusion was evidenced between aspirin and placebo groups (17 $\min [95 \% \mathrm{Cl}, 13.8-19.5]$ vs $16.3 \min [95 \% \mathrm{Cl}, 15.1-17.3]$, respectively) (Supplemental Figure 1A).

Moreover, in order to verify that the route of administration was not responsible for the absence of anti-thrombotic activity of ASA in this model, we reproduced experiments using the i.p. route, which is largely used in preclinical pharmacology in mice, including ASA studies [6], [9], [14]. Similarly to the results obtained with the oral route, and whatever the time to assay after ASA administration (30 min or $3 \mathrm{~h}$ ), we did not observe any effect of i.p.-administered ASA on carotid artery thrombosis, neither for FVB nor for C57BI6 mice (Table 1).

\section{Platelet aggregation and thromboxane generation}

To ensure that the absence of anti-thrombotic effect was not due to a pharmacological inefficacy of a single oral ASA administration for COX-1 inhibition, platelet response to ASA exposure was also evaluated by testing platelet functions ex vivo. Aggregation assays were performed on washed platelets isolated from FVB mice, in response to $5 \mu \mathrm{g} / \mathrm{ml}$ collagen or $1 \mu \mathrm{M}$ U46619, a specific agonist of the TP receptor.

When platelet isolation was done $30 \mathrm{~min}$ after ASA had been administered by the oral route, 
and in line with the results obtained for bleeding time measurement, collagen-induced platelet aggregation was significantly reduced compared to control animals receiving vehicle alone (76\% [95\% Cl, 62-88] vs 34\% [95\% Cl, 20-83] for control and ASA respectively; $P<.01$; Fig $2 \mathrm{~A}$ ). This inhibition of platelet aggregation was associated with a high and significant reduction of about $85 \% \mathrm{TXB}_{2}$ generation by platelets of the ASA group $\left(563 \mathrm{pg} / 10^{8}\right.$ platelets $[95 \% \mathrm{Cl}, 356-1430$ ] vs $81 \mathrm{pg} / 10^{8}$ platelets [95\% Cl, 12-297] for control and ASA respectively; $\mathrm{P}<.001$; Fig $2 \mathrm{~B}$ ).

When ASA was administered $3 \mathrm{~h}$ before platelet isolation, collagen-induced platelet aggregation was still significantly reduced compared to control platelets without ASA (59\% [95\% Cl, 34-89] vs $13 \%$ [95\% Cl, 10-61] for control and ASA respectively; $P<.05 ;$ Fig $2 \mathrm{~A}$ ). Of note, and whereas $\mathrm{TXB}_{2}$ generation in platelet supernatant was also significantly decreased at $3 \mathrm{~h}\left(1058 \mathrm{pg} / 10^{8}\right.$ platelets [95\% Cl, 545-1532] vs $210 \mathrm{pg} / 10^{8}$ platelets [95\% Cl, 82-270] for control and ASA respectively; $P<.05 ;$ Fig $2 \mathrm{~B}$ ), the effect of ASA on platelet response to collagen was less significant compared to the $30 \mathrm{~min}$ time point (Fig 2A). Notably, there was no significant difference in collagen-induced aggregation between the ASA groups ( 30 min vs $3 h ; p=0.25$ ).

The efficacy of aspirin after 4 days administration was also checked by a significant inhibition of collagen-induced washed platelet aggregation ( $82 \% \pm$ SEM $12 \%$ inhibition) and $\mathrm{TXB}_{2}$ generation in the supernatant (97\% \pm SEM 0.4\% inhibition) (Supplemental Figure 1B-C). Overall, platelet inhibition measured ex vivo was more pronounced after ASA repeated administration compared to the single dose.

As a control for platelet responsiveness, aggregation induced by $1 \mu \mathrm{M} U 46619$, which directly activates platelets via the TP receptor independently of TXA 2 synthesis, did not differ whatever the time of blood sampling after ASA delivery to animals $(68 \%[95 \% \mathrm{Cl}, 30-88]$ vs $85 \%[95 \% \mathrm{Cl}$, 
49-92] and $64 \%[95 \% \mathrm{Cl}, 50-78]$ vs $66 \%[95 \% \mathrm{Cl}, 46-22]$ at $30 \mathrm{~min}$ and $3 \mathrm{~h}$ respectively, for control and ASA, respectively; $\mathrm{P}>$.05; Fig 2C).

\section{Discussion}

Since aspirin remains the gold standard of antiplatelet treatment and an unavoidable reference for other antiplatelet molecules under development, this work was designed to settle appropriate in-house conditions to evidence its effects under a single dose regimen on mouse hemostasis. Indeed, there are major discrepancies found in the literature concerning in vivo effects of aspirin in mice. Our present results actually support other studies that failed to demonstrate the antiplatelet effect of ASA in various experimental setups. The two main parameters we chose to evaluate and to settle were $(i)$ the period elapsed between ASA administration and bleeding or thrombosis assays, and (ii) the in vivo test to evaluate drug efficacy.

Regarding the ASA doses to be administered per os in such an evaluation, those that can be found in the literature are more frequently between 5 and $100 \mathrm{mg} / \mathrm{kg}$ [6], [7], [9], [14]-[17]. We show here that a $100 \mathrm{mg} / \mathrm{kg}$ ASA dose increased bleeding time as well as efficiently inhibited platelet activation in vitro, as evaluated by two recognized assays [18]: washed platelet aggregation and $\mathrm{TXB}_{2}$ production. We also used a tenfold lower single dose of $\mathrm{ASA}(10 \mathrm{mg} / \mathrm{kg})$ in some experiments, which turned to result in a high and unacceptable variability in read out data values (data not shown).

Importantly, we analyzed the influence of the period elapsed between ASA administration and 
assays, and how it can affect evaluation of the ASA effect. In some previously reported studies, assays for ASA efficacy were performed between 16 and $24 \mathrm{~h}$ after drug administration [12], [19]. However Evangelista et al. have shown that a significant amount of newly released platelets with a fully active COX were present in the circulation $24 \mathrm{~h}$ after ASA administration [20]. Therefore, and as they are frequently used in published procedures, we focused on two short periods of time, $30 \mathrm{~min}$ and $3 \mathrm{~h}$ after ASA was administered orally. These time-points are in agreement with the rapid ASA effect reported for humans after an oral single dose [21]. Whatever the in vivo or ex vivo endpoint hemostatic test (bleeding time or platelet aggregation), our results show that the $30 \mathrm{~min}$ time point ensures more reproducible results as compared to $3 \mathrm{~h}$. In these conditions, we also show that bleeding time is a better parameter than the blood loss to evidence an effect of ASA on hemostasis.

Considering the demonstration by Schiviz et al. of a variability for hemostatic parameters in mice in the absence of drug exposure, depending on the genetic background even between different strains of C57BI6 [22], we compared the basal and ASA-modulated bleeding parameters in FVB and in C57BI6 (C57BL/6NRj) mice, all males aged 8-12 weeks. We used these genetic backgrounds that correspond to the KO models currently used in our and many other labs [13][23]. Interestingly, in the absence of ASA treatment, bleeding time was significantly about twice shorter for control C57BI6 as compared to FVB mice at $30 \mathrm{~min}$, and thrice shorter at $3 \mathrm{~h}$ (Fig $1 \mathrm{~A}$ vs $1 \mathrm{C}$, black dots). In line, blood loss was also always higher in FVB as compared to C57Bl6 mice at either $30 \mathrm{~min}$ or $3 \mathrm{~h}$ (Fig 1B vs 1D, black dots). In the whole, bleeding experiments appeared to be more predictable-using the C57BI6 (C57BL/6NRj) strain within the limits of the conditions tested. 
Finally, we investigated the impact of ASA on arterial thrombus formation with a commonly used model, the carotid artery thrombosis induced by $\mathrm{FeCl}_{3}$ [11]. Although we used a $15 \% \mathrm{FeCl}_{3}$ concentration for 4 min, we obtained similar results (see Table 1) than Li et al. who found a time to occlusion of $11.3 \pm 3.16$ min when using $7.5 \% \mathrm{FeCl}_{3}$ on $\mathrm{C} 57 \mathrm{Bl} 6$ [24]. Whatever the delay after ASA administration and the mouse strain used, no anti-thrombotic effect of the drug was observed. Therefore, we wondered if this negative result could be due to the administration route. Huang et al. have shown that doses of ASA up to $150 \mathrm{mg} / \mathrm{kg}$ given intravenously were not sufficient to increase the time for occlusion of the mesenteric venule exposed to fluorescein sodium, and that $250 \mathrm{mg} / \mathrm{kg}$ was needed to observe an effect of ASA [15]. In the same study, however, the $150 \mathrm{mg} / \mathrm{kg}$ dose was, nevertheless, found to efficiently increase the tail bleeding time [15]. The same study showed, however, an effect of $40 \mathrm{mg} / \mathrm{kg}$ oral ASA on occlusion time. To note, the study used male ICR mice, a strain we did not use in the present work. Intraperitoneal administration being a commonly used route in pharmacological studies in murine models and ASA treatment [6], [9], [12], [14], [16], [19], [25], we also evaluated this type of administration. However, we did not either observe any effect of ASA on thrombus formation under this particular condition. On the whole, and given that an effective inhibitory activity of ASA on platelet functions was observed ex vivo at $30 \mathrm{~min}$ and at $3 \mathrm{~h}$ (see Fig $2 \mathrm{~A}$ and $2 \mathrm{~B}$ ), we can conclude that the carotid artery thrombosis induced by $\mathrm{FeCl}_{3}$ is not a suitable model for the evaluation of ASA anti-platelet effects, at least within the frame of our experimental conditions. Using the $\mathrm{FeCl}_{3}$ injury model, some authors also failed to show any effect or a very moderate effect of ASA on thrombosis, if any [6], [9], [25], [26]. In a model of femoral artery thrombosis, Kondo et al. showed that ASA can increase the time to occlusion of the artery when thrombosis 
is induced photochemically by using rose Bengal [7], while Nonne et al. failed to show any effect of intravenous ASA in laser-injured mesentery thrombosis in C57BI6 strain [17]. More recently, Adili et al. showed that ASA induced a decreased platelet recruitment into the arterial wall thrombus in a model of laser-induced cremaster artery thrombosis, without affecting the increase in platelet surface P-selectin-expression within thrombi [27]. Thus, taken together, the already published and our current data show a wide variability in response to ASA treatment in arterial thrombosis models in mice. Data currently converge to a lesser contribution of platelets in the $\mathrm{FeCl}_{3}$ injury model compared to mechanical injury; indeed, $\mathrm{FeCl}_{3}$ injury induces significant damage of subendothelial proteins and attachment of platelets to bodies containing ferric ions and exposing large amounts of tissue factor [28].

Limitations of our study are (i) that models using laser to induce carotid injury were not considered, and (ii) that thrombus formation was not monitored using real-time intravital microscopy. Major reason for this is that we wanted to use the more commonly $\mathrm{FeCl}_{3}$ injury model. On purpose, testing of a single ASA administration was firstly considered mostly because the objective of the present study was to evaluate this frequently used procedure, and after having verified that a strong TXA2 generation inhibition was reached after a single dose. However, we cannot exclude that a daily administration of ASA could be more effective in limiting thrombosis. Indeed in a model of thrombus formation induced by in vivo injection of platelet agonist, Armstrong et al. observed that a chronic ASA dosing ( $300 \mathrm{mg} / \mathrm{kg} /$ day for 7 days) reduced thrombus formation [29]. However, more pathophysiologically relevant studies carried out in models of atherothrombosis did not observe an effect of daily administration of ASA on the lesion [5], [10]. To address this controversy, we tested the repeated administration of ASA 
for 4 days in C57BI6 mice. Interestingly, whereas global platelet inhibition measured ex vivo was more pronounced 4 days after ASA repeated administration compared to the single dose, again no difference in time to occlusion was evidenced between aspirin and placebo groups in the carotid thrombosis model (Supplemental Figure 1).

Moreover, it must be noted that, upon completion of our study, a recent publication suggested that the time to occlusion might not be the best parameter in order to analyze arterial thrombosis, and authors suggested including reflow events to maximize data interpretation [28].

Third limitation of our study is that the high dosage of aspirin used is not the one used in chronic treatment in patients with high cardiovascular risk.

We have thus demonstrated that specific experimental conditions are required in order to observe and adequately evaluate the effect of ASA on mouse hemostasis. Here, we show that the most relevant end-point is the tail bleeding time performed with a cut at $3 \mathrm{~mm}$ of the tip and at $30 \mathrm{~min}$ after oral $100 \mathrm{mg} / \mathrm{kg}$ ASA administration to C57Bl6 mice, as our optimal in-house experimental conditions. We do not recommend time to occlusion of $\mathrm{FeCl}_{3}$-induced carotid arterial thrombosis as an index of ASA efficacy on platelets since it is inconsistently altered by ASA. A future consensus debate should define the more relevant method to explore the ASA antithrombotic effect. 


\section{Authorship Details}

B. Decouture conceived the study, performed experiments, analyzed data and wrote the manuscript.

B. Dizier performed animal experiments and analyzed data.

T. Belleville-Rolland and A. Leuci performed in vitro aggregation assays and helped for in vivo experiments.

D Pidard critically read the manuscript.

C Bachelot-Loza and P. Gaussem conceived the study, analyzed data, and wrote the manuscript.

\section{Acknowledgements}

We thank Promex Stiftung für die Forschung for generous funding and for having supported BD as a post-doctoral fellow. We also thank Sonia Poirault-Chassac and Fanny Martin for excellent technical assistance. I Dubail, V Bertrand, C Kharchi and all the technicians from the animal facilities (UMS 3612 CNRS - US25 Inserm, Paris Descartes University).

\section{Fundings}

This work was supported by INSERM, University Paris Descartes and Promex Stiftung für die Forschung Foundation. DP is Chargé de Recherche at the Institut National des Sciences du Vivant from the Centre National de la Recherche Scientifique (CNRS, France).

\section{Declaration of Interest}

The authors have no conflicts of interest to disclose. 


\section{References}

[1] C. Patrono, J. Morais, C. Baigent, et al., Antiplatelet Agents for the Treatment and Prevention of Coronary Atherothrombosis, J Am Coll Cardiol (2017), 70, 1760-1776.

[2] G. J. Roth, N. Stanford, P. W. Majerus, Acetylation of prostaglandin synthase by aspirin, Proc Natl Acad Sci USA (1975), 72, 3073-3076.

[3] M. Hamberg, J. Svensson, B. Samuelsson, Thromboxanes: a new group of biologically active compounds derived from prostaglandin endoperoxides, Proc Natl Acad Sci USA (1975), 72, 2994-2998.

[4] N. Nakahata, Thromboxane A2: Physiology/pathophysiology, cellular signal transduction and pharmacology, Pharmacol Ther (2008), 118, 18-35.

[5] A. J. Cayatte, Y. Du, J. Oliver-krasinski, et al., The Thromboxane Receptor Antagonist S18886 but Not Aspirin Inhibits Atherogenesis in Apo E-Deficient Mice, Arterioscler Thromb Vasc Biol (2000), 20, 1724-1729.

[6] S. S. Smyth, E. D. Reis, H. Väänänen, W. Zhang, B. S. Coller, Variable protection of $\beta 3-$ integrin-deficient mice from thrombosis initiated by different mechanisms, Blood (2001), 98, 1055-1062.

[7] K. Kondo, Y. Suzuki, Y. Ikeda, K. Umemura, Genistein, an isoflavone included in soy, inhibits thrombotic vessel occlusion in the mouse femoral artery and in vitro platelet aggregation, Eur J Pharmacol (2002), 53-57.

[8] S. Grüner, M. Prostredna, B. Aktas, el al., Anti-glycoprotein VI treatment severely compromises hemostasis in mice with reduced $\alpha 2 \beta 1$ levels or concomitant aspirin therapy, 
Circulation (2004), 110, 2946-2951.

[9] X. Wang, P. L. Smith, M. Y. Hsu, M. L. Ogletree, W. A. Schumacher, Murine model of ferric chloride-induced vena cava thrombosis: Evidence for effect of potato carboxypeptidase inhibitor, J Thromb Haemost (2006), 4, 403-410.

[10] C. Schulz, I. Konrad, S. Sauer, et al., Effect of chronic treatment with acetylsalicylic acid and clopidogrel on atheroprogression and atherothrombosis in ApoE-deficient mice in vivo, Thromb Haemost (2008), 99, 190-195.

[11] D. Cherpokova, B. Nieswandt, Mouse models of thrombosis, in: P. Gresele, P. Kleiman, N.S. Lopez, J.A. Page (Ed.) Platelets in Thrombotic and Non-Thrombotic Disorders. Pathophysiology, Pharmacology and Therapeutics: an Update, C. Springer International Publishing, 2017, pp. 681-698.

[12] M. Allende, E. Molina, E. Guruceaga, et al., Hsp70 protects from stroke in atrial fibrillation patients by preventing thrombosis without increased bleeding risk, Cardiovasc Res (2016), $110,309-318$.

[13] B. Decouture, E. Dreano, T. Belleville-rolland, et al., Impaired platelet activation and cAMP homeostasis in MRP4-deficient mice. Blood (2015), 126, 1823-1830.

[14] V. Molina, M. L. Arruzazabala, D. Carbajal, R. Más, Synergistic effect of D-003 and aspirin on experimental thrombosis models, Prostaglandins Leukot Essent Fat Acids (2003), 68, 305310, 2003.

[15] S. W. Huang, H. L. Kuo, M. T. Hsu, et al., A novel thromboxane receptor antagonist, nstpbp5185, inhibits platelet aggregation and thrombus formation in animal models, Thromb Haemost (2016), 116, 285-299. 
[16] Y. Kalish, Z. Malyutin, E. Shai, et al., A mouse model to study thrombotic complications of thalassemia, Thromb Res (2015), 135, 521-525.

[17] C. Nonne, N. Lenain, B. Hechler, et al., Importance of platelet phospholipase C $\gamma 2$ signaling in arterial thrombosis as a function of lesion severity, Arterioscler Thromb Vasc Biol (2005), 25, 1293-1298.

[18] G. Born, C. Patrono, Antiplatelet drugs, Br J Pharmacol (2006), 147, S241-251.

[19] G. J. Broze, A Tail Vein Bleeding Time Model and Delayed Bleeding in Hemophiliac Mice Combined Fresh Frozen Plasma with Recombinant Factor VIla in Restoring Hemostasis for Invasive Procedures in Children with Liver Diseases, Thromb Haemost (2001), 85, 747-748.

[20] V. Evangelista, S. Manarini, A. Di Santo, et al., De novo synthesis of cyclooxygenase-1 counteracts the suppression of platelet thromboxane biosynthesis by aspirin, Circ Res (2006), 98, 593-595.

[21] J. Nagelschmitz, M. Blunck, J. Kraetzschmar, M. Ludwig, G. Wensing, T. Hohlfeld, Pharmacokinetics and pharmacodynamics of acetylsalicylic acid after intravenous and oral administration to healthy volunteers, Clin Pharmacol Adv Appl (2014), 6, 51-59.

[22] A. Schiviz, D. Magirr, P. Leidenmühler, M. Schuster, E. M. Muchitsch, W. Höllriegl, Influence of genetic background on bleeding phenotype in the tail-tip bleeding model and recommendations for standardization: Communication from the SSC of the ISTH, J Thromb Haemost (2014), 12, 1940-1942.

[23] E. Tarantino, P. Amadio, I. Squellerio, et al., Role of thromboxane-dependent platelet activation in venousthrombosis: Aspirin effects in mouse model, Pharmacol Res (2016), 107, 415-425. 
[24] W. Li, M. Nieman, A. Sen Gupta, Ferric Chloride-induced Murine Thrombosis Models, J Vis $\operatorname{Exp}(2016), 115,1-12$.

[25] Y. Kawamura, Y. Takahari, N. Tamura, et al., Imaging of structural changes in endothelial cells and thrombus formation at the site of $\mathrm{FeCl}(3)$-induced injuries in mice cremasteric arteries, J Atheroscler Thromb (2009), 16, 807-814.

[26] N. Faraday, K. Schunke, S. Saleem, et al., Cathepsin G-Dependent Modulation of Platelet Thrombus Formation In Vivo by Blood Neutrophils, PLoS One (2013), 8: e71447.

[27] R. Adili, B. E. Tourdot, K. Mast, et al., First Selective 12-LOX Inhibitor, ML355, Impairs Thrombus Formation and Vessel Occlusion In Vivo With Minimal Effects on Hemostasis, Arterioscler Thromb Vasc Biol (2017), 37, 1828-1839.

[28] A. Eckly, B. Hechler, M. Freund, et al., Mechanisms underlying FeCl3-induced arterial thrombosis. J Thromb Haemost (2011), 9, 779-89.

[29] P. C. Armstrong, N. S. Kirkby, Z. N. Zain, M. Emerson, J. A. Mitchell, T. D. Warner, Thrombosis is reduced by inhibition of COX-1, but unaffected by inhibition of COX-2, in an acute model of platelet activation in the mouse, PLoS One (2011), 6, e20062.

[30] B. Kastetter, A. B. Matrai, B. C. Cooley, Optimizing outcome measurement with murine ferric chloride-induced thrombosis, Blood Coagul Fibrinolysis (2018), 29, 636-643. 
Table 1. In vivo ASA effect on artery thrombosis

\begin{tabular}{ccccccc}
\hline & \multicolumn{3}{c}{$30 \mathrm{~min}$} & \multicolumn{2}{c}{3 hours } \\
\hline Oral & Control & ASA $(100 \mathrm{mg} / \mathrm{Kg})$ & & Control & ASA (100 mg/Kg) \\
\hline FVB & $14.7[10.7-21.2]$ & $17.4[10.3-25]$ & NS & $12.8[9.6-16.5]$ & $14.0[10.5-25]$ & NS \\
\hline C57BI6 & $11.7[8.0-21.1]$ & $14.2[12.3-25]$ & NS & $11.1[9.4-25]$ & $14.4[10.5-16.1]$ & NS \\
\hline & & & & & & \\
\hline I.P. & & & & & & \\
\hline FVB & $11.9[8.9-15.7]$ & $12.5[10.1-17]$ & NS & $10.6[10-11]$ & $11.8[9.6-14.9]$ & NS \\
\hline C57BI6 & $11.4[7.3-14.6]$ & $12.7[7.9-16.2]$ & NS & $10.4[8.2-13.4]$ & $12.5[10.4-15]$ & NS \\
\hline
\end{tabular}

Vehicle or ASA were administered to FVB or C57BI6 mice by the oral or intraperitoneal route (I.P.). Thirty min or $3 \mathrm{~h}$ after ASA administration, carotid artery thrombosis was induced and the time to occlusion was recorded. Results are in minutes and expressed as median $[95 \% \mathrm{Cl}]$. 


\section{Legends to figures}

Figure 1. In vivo ASA effect on bleeding time and blood loss. Bleeding time was measured $30 \mathrm{~min}$ or 3 hours after vehicle (closed circles) or ASA at $100 \mathrm{mg} / \mathrm{kg}$ oral administration (open circles) for FVB $(\mathrm{A} ; n \geq 8)$ or C57BI6 (C; $n \geq 6)$ mice. Hemoglobin concentration in the chamber effluent (containing $10 \mathrm{ml} \mathrm{NaCl} \mathrm{0.9 \% )} \mathrm{following} \mathrm{bleeding} \mathrm{time} \mathrm{was} \mathrm{measured} \mathrm{for} \mathrm{FVB} \mathrm{(B;} n \geq 8$ ) and C57BI6 (D; $n \geq 6)$ mice.

Figure 2. Ex vivo ASA effect on platelet aggregation and $\mathrm{TXB}_{2}$ synthesis. Blood from FVB mice was taken $30 \mathrm{~min}$ or 3 hours after vehicle (closed symbols) or ASA at $100 \mathrm{mg} / \mathrm{kg}$ oral administration (open symbols). Washed platelet aggregation was measured by monitoring OD (405 $\mathrm{nm}$ ) variations of a platelet suspension at a concentration of $3.5 \times 10^{8}$ platelets per milliliter under stirring conditions in response to $5 \mu \mathrm{g} / \mathrm{ml}$ collagen (A1; $n \geq 9$; A2: typical aggregation curves) or $1 \mu \mathrm{M}$ U46619 (C; $n \geq 8$ ). Results are expressed as the percentage of aggregation (seen as a decrease in OD) $300 \mathrm{sec}$ after agonist addition. After collagen-induced aggregation and a centrifugation step, $\mathrm{TXB}_{2}$ was quantified in the supernatant $(\mathrm{B} ; n \geq 5)$, and results are normalized relative to the vehicle condition (Control, grey bars) for each time point. 
Figure 1
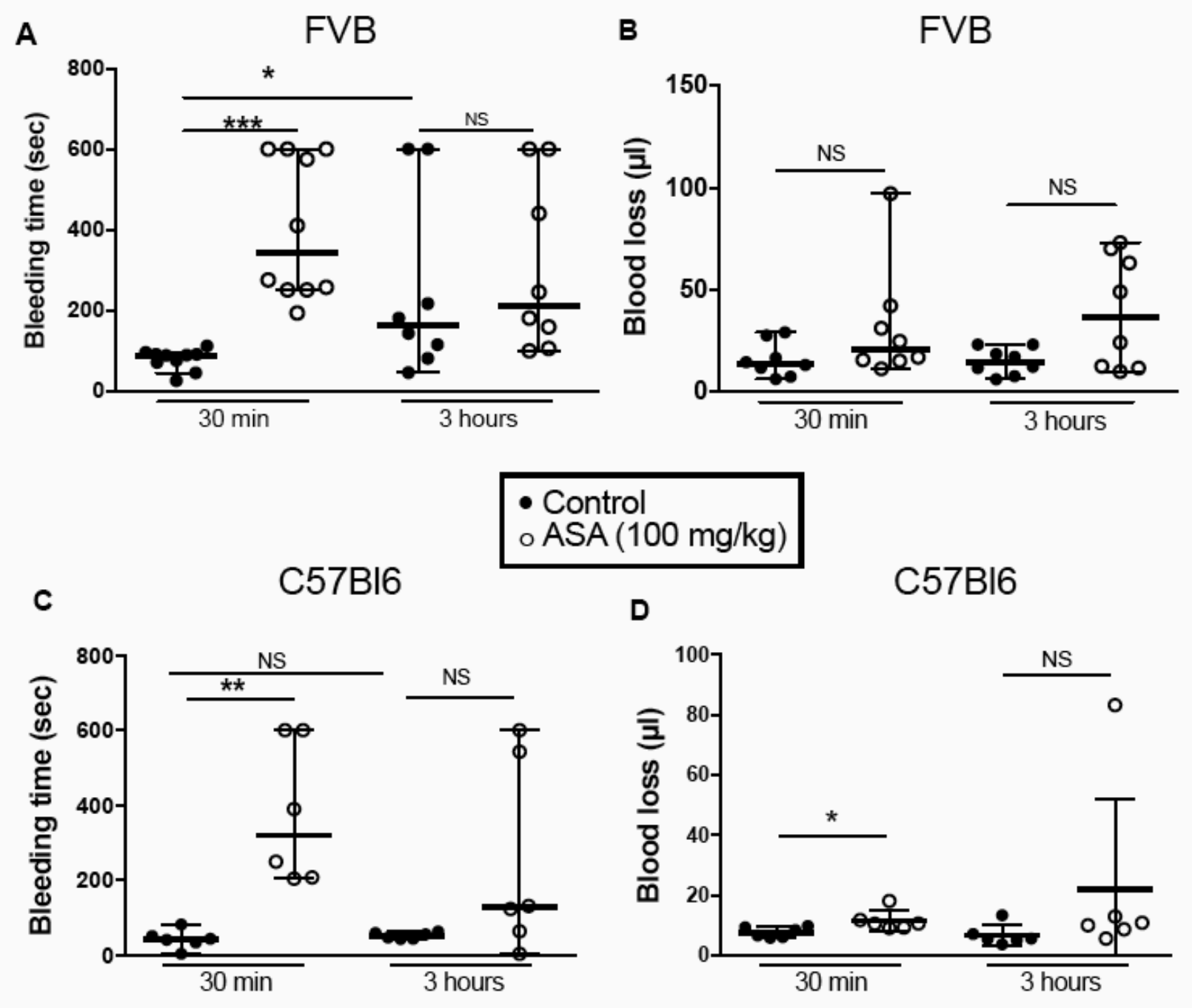
Figure 2
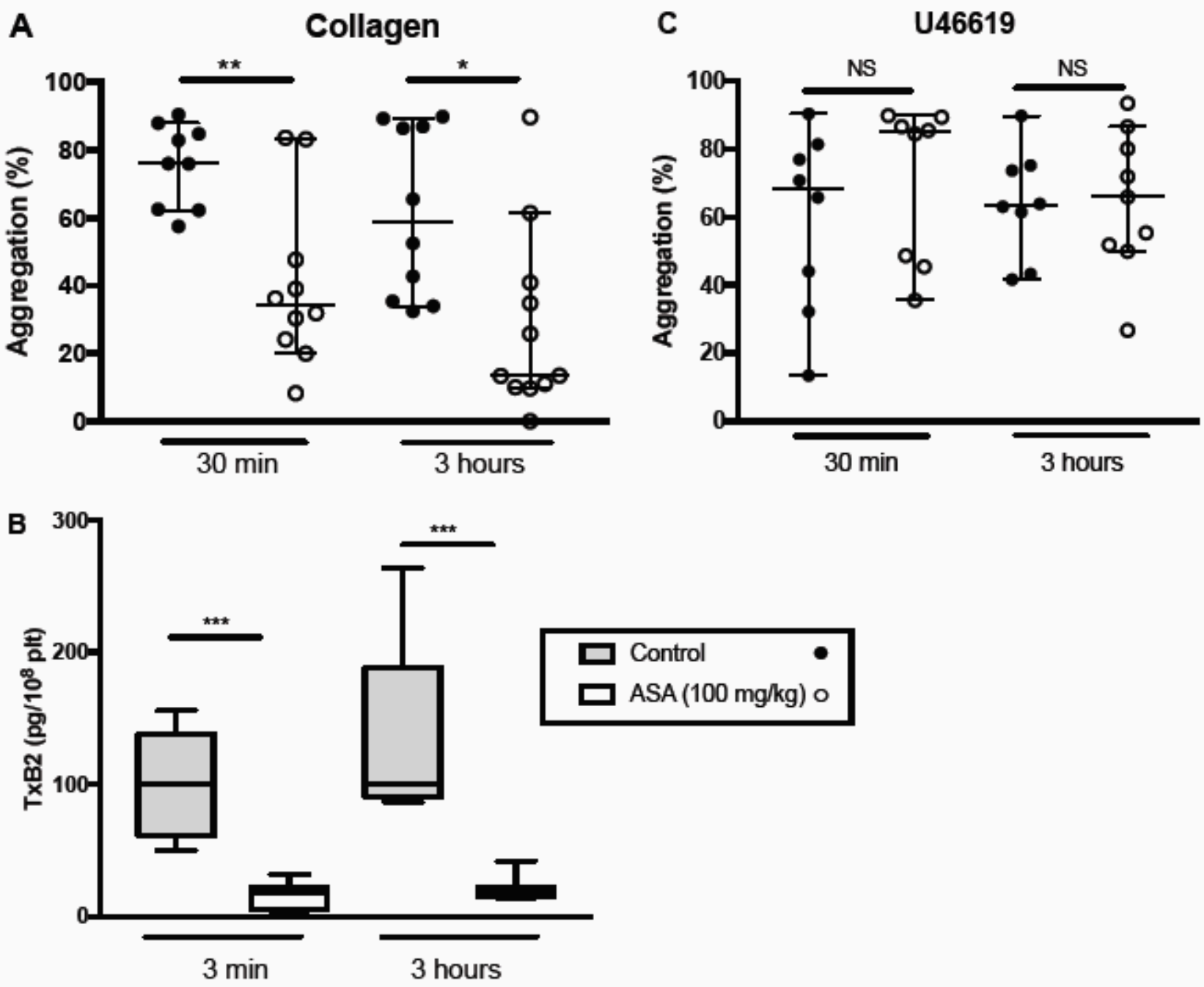